Enferm Bras 2020;19(4):310-6

https://doi.org/10.33233/eb.v19i4.4147

\title{
ARTIGO ORIGINAL Influência do coping religioso-espiritual no luto materno
}

Annaterra Araújo Silva, M.Sc. ${ }^{*}$, Antonio Marcos Tosoli Gomes, D.Sc. ${ }^{*}$, Ana Cristina Santos Duarte, D.Sc. ${ }^{* *}$, Sergio Donha Yarid, D.Sc. ${ }^{* * *}$

*Mestre em Ciências da Saúde com concentração em Saúde Pública pelo Programa de Pósgraduação em Enfermagem e Saúde pela Universidade Estadual do Sudoeste da Bahia (UESB), ** Professor titular da área de Enfermagem em Doenças Contagiosas do Departamento de Enfermagem Médico-Cirúrgico e do Programa de Pós-Graduação em Enfermagem da Faculdade de Enfermagem da Universidade do Estado do Rio de Janeiro (UERJ), ${ }^{* * * P r o f e s s o r a ~ P l e n o ~ d o ~}$ Departamento de Ciência Biológicas da Universidade Estadual do Sudoeste da Bahia (UESB), ${ }^{* * * *}$ Professor Titular da Universidade Estadual do Sudoeste da Bahia (UESB)

Recebido em 20 de maio de 2020; aceito em 26 de agosto de 2020.

Correspondência: Annaterra Araújo Silva, Universidade Estadual do Sudoeste da Bahia (UESB), Avenida José Moreira Sobrinho, s/n, Jequiezinho 45206110 Jequié BA, Brasil

Annaterra Araújo Silva: annaterraraujo@outlook.com

Antonio Marcos Tosoli Gomes: mtosoli@gmail.com

Ana Cristina Santos Duarte: tinaduarte2@gmail.com

Sergio Donha Yarid: yarid@uesb.edu.br

\section{Resumo}

O objetivo deste estudo é avaliar a influência do coping religioso-espiritual no luto materno. É um estudo do tipo transversal de abordagem quantitativa, exploratório e de campo, realizado no município de Caetité/BA. A coleta de dados ocorreu por meio do instrumento de Coping Religioso-Espiritual (CRE), a amostra foi composta por 21 mães que perderam filhos, entre $10 \mathrm{e}$ 30 anos de idade, por causas externas. A análise dos dados foi realizada no Programa Stata (versão 13.0), e a associação encontrada com a situação conjugal foi realizada por meio do Teste de Mann Whitney. Entre as mães avaliadas, a média de idade foi de 54 anos. Prevaleceram mulheres com companheiros $(66,7 \%)$, de cor parda $(57,1 \%)$, alfabetizadas ou com o ensino fundamental completo $(66,7 \%)$, católicas $(76,2 \%)$, exercendo atividade remunerada $(57,1 \%)$ e com renda menor ou igual a um salário mínimo (66,7\%). Evidenciou-se que entre as mães sem companheiro, os fatores, busca de ajuda espiritual P2 $(3,2)$ e busca de outro institucional P5 $(4,0)$ foram mais elevadas. Assim, pode-se afirmar que houve uma intenção de superação, pois a falta do parceiro não impossibilitou que mães enlutadas buscassem apoio espiritual para facilitar seu sentimento de conformação pela morte do filho.

Palavras-chave: Enfermagem, espiritualidade, relações mãe-filho, luto.

\section{Abstract \\ Influence of religious-spiritual coping on mother mourning}

This study aimed to evaluate the influence of Religious-Spiritual Coping on maternal mourning. It is a cross-sectional exploratory field study with quantitative and qualitative approaches, conducted in Caetité/BA. Data collection occurred through the Religious-Spiritual Coping (RSC) instrument; the sample consisted of 21 mothers who lost children from 10 to 30 years old due to external causes. Data analysis was performed using the Stata program (version 13.0), and the association found with the marital situation was performed using the Mann Whitney Test. Among the evaluated mothers, the average age was 54 years old. Prevailed women with partners (66.7\%), brown $(57.1 \%)$, literate or with complete elementary school $(66.7 \%)$, catholic $(76.2 \%)$, exercising paid activity $(57.1 \%)$ and with income less than or equal to one minimum wage $(66.7 \%)$. It was evident that among mothers without a partner, the factors aspects of seeking spiritual help P2 (3.2) and searching for another institutional P5 $(4,0)$ were higher. Thus, there was an intention to overcome, because the lack of a partner did not prevent bereaved mothers seeking spiritual support to facilitate their feeling of conformity for the child's death. 
Keywords: Nursing, spirituality, mother-child relations, bereavement.

\section{Resumen \\ Influencia del coping religioso-espiritual en el luto materno}

El objetivo de este estudio es evaluar la influencia del afrontamiento religioso-espiritual en el luto materno. Se trata de un estudio transversal de enfoque cuantitativo, exploratorio y de campo, realizado en el municipio de Caetité/BA. La recopilación de datos se realizó a través del instrumento Coping Religioso-Espiritual (CRE), la muestra estaba compuesta por 21 madres que perdieron a sus hijos, entre 10 y 30 años, por causas externas. El análisis de los datos se realizó en el Programa de Stata (versión 13.0), y la asociación encontrada con la situación marital se realizó a través de la Prueba de Mann Whitney. Entre las madres evaluadas, la edad media era de 54 años. Prevalecieron las mujeres con pareja $(66,7 \%)$, de color marrón $(57,1 \%)$, alfabetizadas o con educación elemental completa $(66,7 \%)$, católicas $(76,2 \%)$, que ejercían una actividad remunerada $(57,1 \%)$ y con ingresos inferiores o iguales a un salario mínimo $(66,7 \%)$. Era evidente que entre las madres sin pareja, los factores de búsqueda de ayuda espiritual P2 $(3,2)$ y de búsqueda de otro P5 institucional $(4,0)$ eran más elevados. Así pues, puede afirmarse que había una intención de superación, porque la falta de pareja no impedía a las madres en duelo buscar apoyo espiritual para facilitar su sentimiento de resignación ante la muerte de su hijo.

Palabras-clave: Enfermería, espiritualidad, relaciones madre-hijo, aflicción.

O coping é traduzido em português para "enfrentamento", caracterizado por mecanismos criados pelos indivíduos para suportar momentos de pesar e estresse. Distinto de pretextos e de prorrogações para enfrentar situações dolorosas, o coping tem a finalidade de elaborar estratégias físicas ou psíquicas para lidar com a dor e o sofrimento. Isso concede ao indivíduo transcender o trabalho diário de adaptação para uma outra realidade, investindo em novos sonhos e projetos para que o trauma seja esquecido e ressignificado [1].

O Coping Religioso-Espiritual (CRE) é determinado pela influência da religião, espiritualidade ou fé diante do desânimo, depressão e falta de perspectivas. Sua finalidade é resignação, benevolência, resistência e adaptação para aqueles que se apoiam em orações, fé ou espiritualidade através de uma proximidade com um ser superior [2]. Além disso, o CRE está diretamente relacionado à melhoria da qualidade de vida e à promoção do bem-estar [3].

A perda de um filho é apontada na literatura como uma perda essencialmente dolorosa, predispondo a um processo de difícil elaboração [4], pois o elo maternal é interrompido, abrindo espaço para o vazio e a desolação. A compreensão que os pais atribuem à perda pode colaborar na evolução do luto, pois estes vivenciam episódios de indignação e revolta [5].

A dor da morte é incomparável, profunda e particular, encarada de diferentes maneiras pelas mães, enfrentamento este que é refletido na circunstância como se deu a morte dos filhos. Esse processo ocorre no âmbito pessoal e social, e é interpretado de acordo com a relação estabelecida com o filho perdido [6], visto que, mesmo após a morte da prole, as mães não deixam de ser mães, continuam carregando o título da maternidade, diferente das viúvas, viúvos e órfãos, para as mães essa nova identidade não há nome [7].

O luto parental é profundo, difícil e constante, uma vez que a perda rompe com a harmonia dos integrantes da família e compromete as particularidades do lar. Vários efeitos destrutivos podem ser criados na vida dos pais, incluindo crises conjugais, desemprego e isolamento social. Para que estes fatores negativos sejam evitados, os pais devem ser assistidos com o objetivo de se livrar da culpa pela morte do filho [8].

O luto maternal pode permanecer por meses, anos ou jamais terminarem, assim, é importante dar continuidade à vida, ressignificando a perda e buscando incentivos para o equilíbrio. Pesquisas relativas ao luto mostraram resultados negativos de intenso pesar para os pais, envolvendo tensão, separação, manifestações deprimentes e afastamento social das mães [9].

Contudo a morte é um evento que gera um acúmulo de reações ao indivíduo, considerando que o peso da morte não afeta a todos da mesma forma, já que ninguém está preparado para enfrentar uma perda repentina. As mudanças familiares que ocorrem após a perda de um filho são complexas e as estratégias difíceis de serem elaboradas. Nesse sentido, esta pesquisa busca proporcionar a sensibilização para o preparo profissional para lidar com a 
finitude da vida [10]. No entanto, o objetivo deste estudo é avaliar a influência do coping religiosoespiritual no luto materno.

\section{Material e métodos}

$O$ presente trabalho trata-se de um estudo transversal de abordagem quantitativa, exploratório e de campo. A pesquisa foi realizada no município de Caetité, no sudoeste da Bahia, no período de abril a junho de 2019. A amostra da pesquisa foi composta por mães que perderam seus filhos por causas externas da adolescência até o final da fase jovem adulta, compreendida entre 10 e 30 anos de idade.

A coleta de dados ocorreu por meio dos registros arquivados na Secretária de Vigilância Epidemiológica (SVE) para busca dos endereços das mães que perderam seus filhos; àquelas que ainda residiam no município de Caetité, foram realizadas visitas domiciliares com a finalidade de convidá-las para participarem da pesquisa.

Os critérios de inclusão foram atribuídos às mães que vivenciaram a perda de um filho por causas externas (como acidentes de transporte, quedas, afogamentos, contato com animais ou plantas venenosas, envenenamento acidental), com limite mínimo de 1 ano após a perda e, no máximo, 5 anos. E os critérios de exclusão se constituíram para as mães que não aceitaram a participação na pesquisa, que mudaram de endereço, ausência de contato telefônico, óbitos por causas externas de intenção indeterminada, lesões auto infligidas, agressões e intervenção legal [11].

Os registros dos óbitos por causas externas que ocorreram no período entre 2014 e 2019, encontrados na Secretária de Vigilância Epidemiológica (SVE) foram 91 óbitos com idade entre 1 a 98 anos e 39 óbitos de 10 a 30 anos de idade.

A amostra foi composta por 21 participantes seguindo os critérios de inclusão e exclusão, mediante o instrumento de Coping Religioso-Espiritual Breve (CRE-BREVE) que contém 49 itens, sendo 34 relacionados ao CRE positivo e 15 relacionados ao CRE negativo. A escala é utilizada para verificar como os indivíduos utilizam a fé para enfrentar situações estressoras.

O instrumento solicita uma descrição breve da situação de maior estresse que o indivíduo experenciou e exige que o participante responda o quanto fez em cada item para lidar com a situação estressante. As respostas são dadas em escala Likert de 5 (cinco) pontos (1-nem um pouco a 5-muitíssimo) [12].

Dentre os fatores positivos, conforme elaborado por Panzini e Bandeira [12], há uma subdivisão em sete outros fatores correspondentes a estratégias cognitivas e comportamentais específicas de Coping Religioso-Espiritual Positivo (CREP) e, também, fatores negativos que possuem quatro subdivisões referentes às estratégias cognitivas e comportamentais específicas de Coping Religioso-Espiritual Negativo (CREN) como se observa na Tabela I.

Tabela I - Subdivisões correspondentes as estratégias cognitivas e comportamentais específicas de CREP e do CREN.

\begin{tabular}{llll}
\hline CREP & CREN & \\
\hline P1 & Transformação de si/Sua vida & N1 & $\begin{array}{l}\text { Reavaliação negativa de } \\
\text { Deus }\end{array}$ \\
P2 & Busca de ajuda espiritual & N2 & $\begin{array}{l}\text { Posição Negativa frente a } \\
\text { Deus }\end{array}$ \\
P3 & Oferta de ajuda a outro & N3 & $\begin{array}{l}\text { Insatisfação com outro } \\
\text { institucional } \\
\text { Reavaliação negativa do } \\
\text { significado }\end{array}$ \\
P4 & Posição positiva frente a Deus & N4 & \\
P5 & $\begin{array}{l}\text { Busca de outro institucional } \\
\text { Afastamento através de }\end{array}$ & & \\
P7 & $\begin{array}{l}\text { Deus/Religião/Espiritualidade } \\
\text { Busca de conhecimento espiritual }\end{array}$ & & \\
\hline
\end{tabular}

Fonte: Elaborada pelos autores com base na Grade de Levantamento Cre-Breve.

Posteriormente, os resultados são classificados a partir do parâmetro utilizado para análise dos valores das médias de CRE, conforme a Tabela II. 
Tabela II - Parâmetros da Escala CRE-breve.

\begin{tabular}{ll}
\hline Médias de CRE & \\
\hline Nenhuma ou Irrisória & 1,00 a 1,50 \\
Baixa & 1,51 a 2,50 \\
Média & 2,51 a 3,50 \\
Alta & 3,51 a 4,50 \\
Altíssima & 4,51 a 5,00 \\
\hline Fonte: Panzini e Bandeira [12].
\end{tabular}

A pesquisa foi realizada de acordo com a Resolução 466, de 12 de dezembro de 2012, do Conselho Nacional de Saúde (CNS) [13], que aborda os aspectos éticos da pesquisa envolvendo seres humanos. Este estudo faz parte de um projeto intitulado "A influência da bioética e da espiritualidade na saúde" aprovado no Comitê de Ética em Pesquisa (CEP) com Certificado de Apresentação para Apreciação Ética (CAAE) no 32197814.9.0000.0055, sob o número de Parecer 1.949.549.

\section{Resultados}

Entre as mães avaliadas, a média da faixa etária foi de 54 anos, variando de 37 a 69 anos de idade. Prevaleceram mulheres com companheiros $(66,7 \%)$, de cor parda $(57,1 \%)$, alfabetizadas ou com ensino fundamental completo $(66,7 \%)$, católicas $(76,2 \%)$, exercendo atividade remunerada $(57,1 \%)$ e com renda menor ou igual a um salário mínimo $(66,7 \%)$, (Tabela III).

Tabela III - Caracterização das mães enlutadas avaliadas, Caetité/BA, 2019.

\begin{tabular}{lll}
\hline & $\mathrm{N}$ & $\%$ \\
\hline Situação conjugal & & \\
\hline Com companheiro & 14 & 66,7 \\
Sem companheiro & 7 & 33,3 \\
Cor & 12 & \\
Parda & 8 & 57,1 \\
Branca & 1 & 38,1 \\
Indígena & & 4,8 \\
\hline Escolaridade & 14 & 66,6 \\
\hline Alfabetizada/Ensino Fundamental I & 1 & 4,8 \\
Ensino Fundamental II & 6 & 28,6 \\
Ensino Médio completo & & \\
\hline Religião & 16 & 76,2 \\
\hline Católica & 5 & 23,8 \\
Evangélica & & \\
\hline Exerce atividade remunerada & 12 & 57,1 \\
\hline Sim & 9 & 42,9 \\
Não & & \\
Ren da & 14 & 66,6 \\
< 1 Salário mínimo & 6 & 28,6 \\
1 a 3 salários mínimos & 1 & 4,8 \\
4 a 7 salários mínimos
\end{tabular}

Quanto à avaliação do CRE total, a mediana foi de 3,8 (IQ 3,7-4,1), observando o CRE positivo e negativo, as medianas foram respectivamente 3,7 (3,6-4,1) e 2,1 (1,9-2,5); na classificação proposta, nota-se que 17 mães $(81,0 \%)$ foram consideradas como CRE alto ou altíssimo e 4 (19,0\%) como médio.

A análise dos dados foi realizada no Programa Stata MP (versão 13.0). As variáveis categóricas se apresentaram em frequência relativa e absoluta, enquanto as variáveis contínuas em mediana e intervalo interquartil, ou média e desvio padrão. Dada a não normalidade dos dados provadas por meio do Teste de Shapiro Wilk, a comparação de diferença dos domínios do CRE de acordo com a situação conjugal foi realizada por meio do Teste de Mann Whitney, assumindo nível de significância de 5\% para todas as análises. 
Tabela IV - Comparação das medianas dos domínios do CRE de mães enlutadas com e sem companheiro, Caetité/BA, 2019.

\begin{tabular}{llllll}
\hline & \multicolumn{4}{l}{ Com companheiro } & \multicolumn{2}{l}{ Sem companheiro } & \\
\cline { 2 - 5 } & Mediana & IQ & Mediana & IQ & 0,12 \\
CRE + & 3,6 & $3,5-4,1$ & 4,0 & $3,8-4,1$ & 0,44 \\
CRE - & 2,3 & $1,9-2,5$ & 2,0 & $1,8-2,3$ & $0,02^{*}$ \\
CRET & 3,7 & $3,5-3,9$ & 4,0 & $3,8-4,2$ & 0,53 \\
P1 & 4,0 & $3,7-4,4$ & 4,0 & $3,9-4,8$ & $0,04^{*}$ \\
P2 & 2,7 & $2,4-3,2$ & 3,2 & $3,0-3,6$ & 0,85 \\
P3 & 3,7 & $3,0-4,0$ & 3,8 & $2,9-4,2$ & 0,48 \\
P4 & 4,8 & $4,8-5,0$ & 5,0 & $4,7-5,0$ & $0,04^{*}$ \\
P5 & 3,0 & $2,8-4,0$ & 4,0 & $3,9-4,6$ & 0,25 \\
P6 & 4,7 & $4,3-5,0$ & 5,0 & $4,6-5,0$ & 0,11 \\
P7 & 3,0 & $2,3-3,7$ & 3,7 & $3,3-3,8$ & 0,32 \\
N1 & 1,8 & $1,0-2,4$ & 1,0 & $1,0-1,7$ & $>0,36$ \\
N2 & 4,0 & $3,3-4,7$ & 4,0 & $3,8-5,0$ & $>0,58$ \\
N3 & 1,8 & $1,5-3,0$ & 2,0 & $1,6-2,6$ & $>0,36$ \\
N4 & 1,8 & $1,0-3,3$ & 1,3 & $1,0-1,5$ & \\
\hline
\end{tabular}

*Diferença estatisticamente significante pelo teste de Mann Whitney.

Evidenciou-se que entre as mães sem companheiro, as medianas do CRET $(4,0)$ e dos fatores P2 $(3,2)$ e P5 $(4,0)$ foram mais elevadas, sendo a diferença para as mães com companheiro estatisticamente significante, conforme se apresenta na Tabela IV.

\section{Discussão}

Busca por ajuda espiritual e busca por outro institucional

O modo como o indivíduo elabora o luto está associado ao modo como a sociedade no qual este está inserido manifesta-se diante da perda [7]. As reações diante da morte ocorrem quando o enlutado percebe que é necessário perder o interesse pelo objeto perdido, buscando um novo propósito de vida [14].

Compreende-se que as mortes por causas externas se revelam como uma dolorosa experiência para as mães, uma vez que se trata de uma morte inesperada e repentina. As mães que vivenciam este difícil enfrentamento podem ter uma resolução do luto mais demorada. Isso ocorre devido à falta de apoio espiritual, convívio social, ausência da família e despreparo profissional, fazendo com que muitas mães se sintam isoladas e culpadas [9].

As mães passam por situações dolorosas até conseguir dar seguimento à vida. $\mathrm{A}$ espiritualidade dessa forma é vista como uma das mais importantes estratégias para auxiliar o indivíduo a elaborar a perda e buscar meios para construir planos sem perder seus propósitos, acreditando em uma força superior para aliviar suas angústias [15].

Deste modo, para que ocorra a resolução das dificuldades decorrentes da elaboração do processo do luto, é necessário que as mães estejam rodeadas de pessoas aptas à escuta qualificada e que este ambiente seja acolhedor para que seus pensamentos sejam expressos e compartilhados [16], dessa forma os familiares também exercem papel fundamental na elaboração do luto para que as mães não se afastem do seu convívio social e perca o interesse pelas atividades diárias [8].

Por fim é necessário que as mães compreendam que o enfretamento espiritual particular, não necessariamente deve ocorrer em ambientes sociais destinados para essa procura, mas em qualquer lugar onde ela possa aprofundar suas inquietações e anseios [17], pois os mecanismos para dar continuidade à vida são planejados e adaptados conforme as particularidades vivenciadas por cada indivíduo [4].

\section{Situação conjugal e luto materno}

Embora o enfrentamento do luto aconteça de acordo com as particularidades de cada mãe, ele sofre interferência de vários elementos, como a assistência fornecida a este individuo, se ela é percebida e aproveitada. Nesse sentido o suporte do parceiro pode auxiliar as mães para que estas suportem a dor e consigam expressar seus sentimentos, possibilitando situações 
de descontração e lazer, de modo que a compreensão e o enfrentamento do luto aconteçam de forma conjunta e saudável [8].

A partir dos dados encontrados neste estudo, as mães enlutadas que davam seguimento a vida sem o auxílio do parceiro utilizavam estratégias de enfrentamento religioso-espiritual para a elaboração do luto e superação da perda, através da fé, orações e crença em um ser superior [1]. Por outro lado, as mães sem companheiro apresentaram uma reavaliação negativa de Deus e uma reavaliação negativa do significado, comparado as mães que seguiam com auxílio do parceiro.

Contudo ao encarar a perda de um filho, o casal se depara com uma difícil situação, no qual ambos precisam ressignificar suas dores para que a união encontre forças e estímulos. Mas em muitas famílias, o pai se sente encarregado de ser o cuidador e provedor do bem-estar da família, não se permitindo o sofrimento necessário para aceitar e compreender esta etapa, pois muitas vezes não é levado em consideração os sentimentos do pai e suas reações diante dessa perda [18].

Por isso as mães por muito tempo se sentem culpadas, tanto pela morte prematura dos filhos quanto pela crise conjugal. Nesse sentido os conjugues podem estar vivenciando fases diferente do processo do luto, surgindo desarranjos entre o casal, o que poderia justificar os dados encontrados nesta pesquisa através das mães com companheiro que não percebem a necessidade de um ambiente seguro no qual possam relatar suas necessidades, sentimentos e comportamentos do casal [19].

\section{Conclusão}

Conforme o estudo realizado, a influência do coping religioso-espiritual no luto materno foi imprescindível na maneira como as mães percebiam e lidavam com a morte do filho. Entretanto a espiritualidade demonstrou ser um importante mecanismo de resiliência e busca pelo novo propósito de vida, despertando nas mães pensamentos positivos diante de experiências complexas e de difícil aceitação, auxiliando-as no enfrentamento diário.

Contudo, a contribuição desta pesquisa em esclarecer a influência do coping religiosoespiritual no luto materno dá-se com a compreensão que houve uma intenção de superação, visto que ao procurar apoio espiritual através de outras pessoas ou outras instituições das quais já faziam parte, a falta do parceiro não impossibilitou que essas mães utilizassem estratégias para assimilarem a perda e refazerem seus planos.

1. Gonçalves OS, Bittar CLM. Estratégias de enfrentamento no luto. Mudanças 2016;24(1):39-44. https://doi.org/10.15603/2176-1019/mud.v24n1p39-44

2. Silveira OS, Azambuja LS. A influência da religiosidade e espiritualidade no enfrentamento da doenca. Psicologia 2017;1-22.

3. Guerra GM, Oliveira JC, Fistarol IRB, Vieira M, Deodato S, Tsunemi MH. Religiosity index and quality of life in the search for better blood pressure control. Mundo saúde 2018:42(4):932-957. https://doi.org/10.15343/0104-7809.20184204932957

4. Frizzo HC, Bousso RS, Ichikawa CR, Sá NN. Mães enlutadas: criação de blogs temáticos sobre a perda de um filho. Acta Paul Enferm 2017:30(2):116-21. https://doi.org/10.1590/1982-0194201700019

5. Jacinto HMC, Santos JS, Silva TDS, Kabengele DC. A experiência de mães após a morte da criança. CHSR 2018;4(3):43-54.

6. Coelho Filho JF, Lima DMA. Luto parental e construção identitária: compreendendo o processo após a perda do filho. Psicol Argum 2017;35(88):16-32. https://doi.org/10.7213/psicolargum.35.88.AO02

7. Dahdah DF, Bombardab TB, Frizzoc HCF, Joaquim RHVT. Revisão sistemática sobre luto e terapia ocupacional. Cad Bras Ter Ocup 2019;27(1):186-96. https://doi.org/10.4322/2526-8910.ctoar1079

8. Andrade ML, Mishima-Gomes FKT, Barbieri K. Recriando a vida: o luto das mães e a experiência materna. Psicol Teor Prat 2017;19(1):21-3. https://doi.org/10.5935/19806906/psicologia.v19n1p33-43

9. Franqueira AMR, Magalhães AS. Compartilhando a dor: o papel das redes sociais no luto parental. Revista Pesquisa Qualitativa 2018;6(11):373-89. https://doi.org/10.33361/RPQ.2018.v.6.n.11.172 
10. Grizafis NA, Baumkarten ST. Luto em Santa Maria: estudo da tragédia sob um olhar sistêmico. Pensando Fam 2018;22(2):105-20. Disponível em:

http://pepsic.bvsalud.org/scielo.php?script=sci arttext\&pid=S1679494X2018000200008\&lng=pt\&nrm=iso

11. Sandler I, Tein JY, Cham H, Wolchik S, Ayers T. Long-term effects of the Family Bereavement Program on spousally bereaved parents: grief, mental health problems, alcohol problems, and coping efficacy. Dev Psychopathol 2016;28:801-18. https://doi.org/10.1017/S0954579416000328

12. Panzini RG, Bandeira DR. Escala de Coping religioso-espiritual (escala CRE): elaboracão e validação de construto. Psicol Estud 2005;10(3). https://doi.org/10.1590/S1413-73722005000300019

13. Brasil. Ministério da Saúde. Conselho Nacional de Saúde. Resolução $n^{\circ}$ 466, de 12 de dezembro de 2012. Trata de pesquisas em seres humanos. Brasília: Ministério da Saúde; 2012.

14. Pereira SM, Pires EF. As experiências de perdas e luto na contemporaneidade: um estudo bibliográfico. Revista Educacão 2018;13(1):200-17.

15. Almeida TCS. Espiritualidade e resiliência: enfrentamento em situacõos de luto. Sacrilegens 2015;12:72-91.

16. Santos RCC, Yamamoto YM, Custódio LMG. Aspectos teóricos sobre o processo de luto e a vivência do luto antecipatório. Psicologia 2017;1-18.

17. Tomás CF. Estratégias de coping religioso: a espiritualidade como fator promotor de saúde e bem-estar. Revista INFAD de Psicología 2015;2(1):483-90.

18. Delalibera M, Joana Presa J, Coelho A, Barbosa A, Franco MHP. A dinâmica familiar no processo de luto: revisão sistemática da literatura. Ciênc Saúde Colet 2015:20(4):1119-34. https://doi.org/10.1590/1413-81232015204.09562014

19. Santos SH, Oliveira W, Jesus CF. Pais enlutados na sociedade atual: uma análise sobre suas vivências cotidianas a partir de novos critérios diagnósticos. Revista Ciências Humanas 2015;8(1):98-108. https://doi.org/10.32813/21791120.2015.v8.n1.a251 